\title{
Randomized Controlled Trial
}

Authors and affiliations: John Mackintosh ${ }^{1}$, Grace Cone ${ }^{2}$, Kate Harland ${ }^{2}$ and Krishna B Sriram $^{2,3}$

${ }^{1}$ Department of Thoracic Medicine, The Prince Charles Hospital, Rode Road, Chermside, QLD 4032

2 Department of Respiratory Medicine, Gold Coast University Hospital, 1 Hospital Boulevard, Southport, Queensland, 4215

${ }^{3}$ School of Medicine, Parklands Drive, Griffith University, Southport, Queensland 4215, Australia

\section{*Corresponding author:}

Associate Professor Krishna B Sriram

Department of Respiratory Medicine, Gold Coast University Hospital

1 Hospital Boulevard, Southport, QLD, Australia 4215.

Email: bajeekrishna@gmail.com; Phone: +61 756780250

Running title: Music Reduces Pleural Procedure Anxiety

Conflict of interest: The authors have no conflicts of interest.

\section{Keywords:}

Pleural Disease

This article has been accepted for publication and undergone full peer review but has not been through the copyediting, typesetting, pagination and proofreading process, which may lead to differences between this version and the Version of Record. Please cite this article as doi: 10.1111/imj.13738 
Procedures

Anxiety

Music

\author{
Abbreviations list \\ STAI: State Trait Anxiety Inventory STAI \\ ACTRN: Australian New Zealand Clinical Trials Registry \\ GCUH: Gold Coast University Hospital GCUH \\ VAS: Visual Analogue Scale VAS \\ SPSS: Statistical Package for Social Sciences
}

Acknowledgments: The authors would like to thank to all the study participants. We also thank the medical and nursing staff of the respiratory ward at the Gold Coast University Hospital without whose assistance this study would not have been completed.

Guarantor KBS takes responsibility for the content of the manuscript, including the data and analysis.

Author contributions: KBS had full access to all of the data in the study and takes responsibility for the integrity of the data and the accuracy of the data analysis. KBS, JM, GC, KH contributed substantially to the study design, data analysis and interpretation, and the writing of the manuscript.

Financial/nonfinancial disclosures: NIL

\title{
Abstract
}


Background: Patient anxiety is an often overlooked complication of pleural diagnostic and therapeutic procedures. Listening to music is effective in reducing patient anxiety in some endoscopy procedures but has not yet been evaluated in pleural procedures. Methods: Consecutive patients undergoing therapeutic pleural procedures were randomised to music and control groups. Participants in the music group listened to self selected music using ear-bud headphones for the duration of the procedure. State anxiety was assessed before and after the procedure using the State Trait Anxiety Inventory (STAI). Physiological parameters were also measured. Results: 60 patients were included in the study. In the music group, a reduction in State Anxiety Scores were observed post-procedure (34 \pm 11 vs. 48 $\pm 13, \mathrm{p}<0.001$ ) while no change was observed in the Control group ( $40 \pm 11$ vs. $42 \pm 11$, $\mathrm{p}=0.51)$. Participants in the music group had reductions in heart rate $(87 \pm 17$ vs. $95 \pm 15$, $\mathrm{p}=0.04)$, systolic ( $121 \pm 13$ vs. $130 \pm 16, \mathrm{p}=0.02)$ and diastolic blood pressure ( $72 \pm 8$ vs. $78 \pm 9$, $\mathrm{p}=0.01$ ) post procedure compared to the pre-procedures values. A similar change was not detected in the control group: heart rate $(86 \pm 17$ vs. $85 \pm 15$, $\mathrm{p}=0.73)$, systolic $(133 \pm 21$ vs. $134 \pm 20, \mathrm{p}=0.83)$ and diastolic blood pressure $(77 \pm 9$ vs. $79 \pm 10, \mathrm{p}=0.30)$. There was no difference in patient pain scores $(p=0.8)$, willingness to undergo the procedure again $(p=0.27)$, satisfaction with the performance of the pleural procedure $(p=0.20)$ and duration of the procedure $(\mathrm{p}=0.68$ ) between the music and control groups. Conclusions: Listening to music appears to be beneficial in reducing anxiety in patients undergoing pleural procedures.

Clinical Trial Registration: Australian New Zealand Clinical Trials Registry; ACTRN12615001325594 (www.anzctr.org.au). 


\section{Introduction}

Pleural aspiration (diagnostic or therapeutic) and intercostal tube insertion are important diagnostic and therapeutic tools for the management of patients with pleural effusions. Commonly recognised complications of pleural procedures include pneumothorax, persistent air leak, re-expansion pulmonary oedema, intrapleural haemorrhage and malignant metastatic seeding (1). However an often overlooked complication of any invasive medical procedure, such as pleural procedures, is patient anxiety (2). Anxiety may be related to the symptoms of an underlying disease, the uncertainty of diagnosis, fear that the procedure would be painful, and fear of the unknown or unexpected $(3,4)$. A high level of anxiety may result in a more difficult procedure, an incomplete procedure and additional use of analgesic and/or sedative medication (5). Reduction in state anxiety prior to and during an invasive medical procedure may help promote relaxation and possibly decrease the frequency of some complications during the procedure. Interestingly other medical procedures such as gastroscopy, colonoscopy, cystoscopy, colposcopy and bronchoscopy have all been shown to be stressful for patients due to anxiety, discomfort, and even a previous unpleasant experience (5-17).

In order to decrease the level of pain associated with interventions such as pleural procedures, sedative and analgesic drugs are sometimes offered, although their use is associated with increased risk of complications (18). Music has been acknowledged as a safe and effective non-pharmacological anxiolytic agent due to its effect on the perception of pain and anxiety reducing the regular pharmacological sedative doses (19). A recent meta-analysis on the effect of music during endoscopy procedures has shown a beneficial effect of reducing anxiety and pain in patients undergoing endoscopy procedures, with a possible exception of patients undergoing colposcopy and bronchoscopy (20). Yet within 
the realm of pleural procedures, patients' listening to music as an intervention to reduce pain and anxiety has not been examined. This study aims to evaluate whether listening to music during pleural procedures reduces patients’ anxiety.

\section{Methods}

\section{Study Design and Participants}

The study was a prospective randomized controlled study performed at the Gold Coast University Hospital (GCUH). Consecutive patients who were required to undergo a pleural procedure, specifically therapeutic pleural aspiration, intercostal chest tube insertion and tunnelled pleural catheter were considered for the study. Patients were excluded if they were below 18 years old, unable to provide written consent, they had impaired hearing, if the pleural procedure was being performed as a medical emergency, or if the procedure was performed on the weekend or outside of usual working hours (8am-5pm). All patients scheduled to undergo pleural procedures were given standardized written and verbal information about the pleural procedure and the research study. Consenting patients were randomized to either the music group or control (no music) group. Study participants were randomized based on the results of block randomisation, a method used in previous studies evaluating the benefits of music during procedures $(14,16)$, using a web-based sequence generator (https://www.randomizer.org). The study was registered on the Australian New Zealand Clinical Trials Registry (ACTRN12615001325594). The Gold Coast Health Services District Human Research Ethics Committee approved the study (HREC/16/QGC/1). 


\section{Intervention}

Potential study participants were invited to participate in the study. Written informed consent was obtained and randomisation was performed on consenting participants. Participants randomized to the music group were allowed to listen to music of their choice that was freely available on a popular video-sharing website and the music was delivered via a laptop computer. Participants listened to the music via ear-bud headphones and the music was played during the entire duration of the pleural procedure and for an additional 10 minutes before and 10 minutes after the pleural procedure. Local anaesthetic (lignocaine) was administered to all patients. At our institution the majority of ward-based pleural procedures are performed by advanced trainees (post-graduate year (PGY) 4+) in respiratory medicine or respiratory consultants. In instances where house officers (PGY 2-4) perform pleural procedures, it is mandatory that they be supervised by the advanced trainee and/or respiratory consultant.

\section{Measurements}

The primary outcome measure was change in anxiety post-procedure. The secondary outcome measures were changes in the heart rate, systolic and diastolic blood pressure before and after completion of the pleural procedure and duration of procedure (calculated from the time at which the patient was positioned for ultrasound to when dressings had been applied and the patient was able to move freely). Procedure-related anxiety was measured using the State-Trait Anxiety Inventory (STAI) (21) scale within 1 hour before the pleural procedure and repeated again within $1 \mathrm{~h}$ after completing the pleural procedure. Instructions pertaining to this self-administered questionnaire were provided to each patient by a nurse specially trained in questionnaire administration. The state anxiety scale (state) consists of 20 questions that determine how the respondents "feel right now." The trait anxiety scale (trait) consists of 20 questions that assess how the respondents "generally 
feel.” The pre-questionnaires were completed before the operator entered the room and the post questionnaires completed after the operator left the room. The questionnaires were scored by adding the weighted (1 to 4) scores of each item using the directions and scoring key provided in the Manual for the State-Trait Inventory. The scores could vary from a minimum of 20 to a maximum of 80 . At the end of the pleural procedure, patients were asked to rate their overall feelings of pain, satisfaction and willingness to undergo procedure using a Visual Analogue Scale (VAS), similar to the scales used in previous studies evaluating the benefits of music during procedures $(11,14)$. Complications of pleural procedures that were considered for the study included peri or post procedure vasovagal syncope, iatrogenic haemothorax and pneumothorax and pleural space infection.

\section{Statistical Analysis}

All statistical analyses were performed using SPSS (Version 21, SPSS Inc., Chicago, USA). Demographics and comparability of the treatment and control groups were assessed using the paired $t$ test for continuous variables and the chi-square test for categorical variables. For interval-level assessments the Mann-Whitney U test was used to assess differences between pre- and post-pleural procedure STAI scores. Statistical significance was determined at the 0.05 level and confidence intervals (CIs) set at 95\% probability. Power calculations performed to determine the minimum sample size for a set a (0.05) and SD (set at 10.4, the SD for State Trait Anxiety Inventory-State (STAI-S) scores of working adults). On the basis of our knowledge of the literature and of the STAI scale, we fixed a clinically significant difference in STAI scores at 5. Power calculations determined that a sample size of 60 patients would provide a power coefficient of 0.96 . 


\section{Results}

Contact was made with 94 eligible participants between April 2015 and July 2016 (Figure 1). After exclusions, randomisation was performed on 60 participants who provided written consent and were recruited to the study. 30 participants were randomized to the music group and 30 participants to the control group. The characteristics of the study participants are presented in Table 1 . There were slightly more males (55\%) in the control group but the difference was not significant. Most patients were elderly with the mean age $( \pm$ standard deviation (SD) of the study cohort being $67( \pm 14)$ years. About two-thirds of the participants had the pleural procedure performed on the right hemi-thorax. One-third of participants stated that they had undergone at least one or more pleural procedures previously. Inter-costal catheter insertion was the most common pleural procedure in this study accounting for approximately $75 \%$ of all the pleural procedures performed. Malignant pleural effusion (65\%) was the most common indication for the procedure. No pleural procedure related complications were noted in the study cohort and no procedures were prematurely aborted.

Prior to performing the pleural procedure, there was no difference between the two groups in terms of state or trait anxiety scores and blood pressure. Procedure duration, pain scores and patient satisfaction with procedure were similar between the two groups (Table 2). Participants in the control group had slightly lower baseline pulse rate (85bpm vs. 95bpm, $\mathrm{p}=0.01$ ). After the procedure was completed, participants in the music group had lower State Anxiety Scores compared to their pre-procedure scores ( $34 \pm 11$ vs. $48 \pm 13, \mathrm{p}<0.001$ ) (Figure 2a). There was no significant difference in the control group ( $40 \pm 11$ vs. $42 \pm 11$, $\mathrm{p}=0.51$ ) (Figure 2b). The pre- and post-procedure Trait Anxiety Scores were not significantly different in both the music group and the control group $p=0.64$ ) 
(Supplementary Figure 1). Similarly, patients in the music group had lower post-procedure pulse rate $(\mathrm{p}=0.04)$, systolic blood pressure $(\mathrm{p}=0.02)$ and diastolic blood pressure $(\mathrm{p}=0.01)$ (Figure 3) compared to pre-procedure values. In the control group, there was no change in the post and pre-procedure physiological measurements (Figure 3).

\section{Discussion}

Anxiety is an under-recognised complication of invasive medical procedures, such as pleural procedures. In instances where a patient with a pleural effusion is undergoing the pleural procedure for both diagnostic and therapeutic purposes there may also be anxiety about the underlying cause of the effusion. Heightened anxiety may translate to adverse physiological consequences, such as increased blood pressure and heart rate, high blood cortisol levels leading to slower wound healing, diminished immune response and increased risk of infection (22). This study confirms that patients experience significant state anxiety prior to undergoing a pleural procedure. Prior research suggests that high levels of anxiety may have a significant impact on procedure outcomes in addition to the obvious impact of anxiety to the patient (5). It is also intriguing that physicians and their assistants may not be very good at identifying the severity of anxiety and discomfort patients experience during procedures $(6,23)$.

A common approach to the management of procedure related anxiety is the administration of sedatives and analgesic medications. However the use of these medications for alleviating anxiety in patients at risk of respiratory depression may be hazardous (1). Similar concern in the peri-operative setting has prompted the search of nonpharmacological interventions to reduce anxiety $(24,25)$. Provision of ambient music and music therapy (implemented by trained music therapists) are slowly gaining acceptance 
among healthcare professionals as a non-pharmacological anxiolytic intervention (26). To date, there have been at least four Cochrane systematic reviews that have found that music is effective in reducing anxiety in patients with coronary heart disease (27), during mechanical ventilation (28), in patients with malignancy (29) and during surgery (30).

Our study supports the use of music as adjunctive therapy in reducing anxiety in patients undergoing pleural procedures. Patients in the music group demonstrated a significant reduction in state anxiety at the conclusion of the pleural procedure. The baseline level of anxiety, as measured by trait anxiety, was similar in both groups and did not change after the procedure. Hence the two groups (music and control) were relatively matched in terms of predisposition to anxiety. The lack of any change in trait anxiety strengthens the intertest validity of the STAI questionnaire. In addition to reductions in state anxiety, patients in the music group demonstrated significant reductions in physiological markers of pain and anxiety including heart rate and blood pressure. There was no significant physiological change in the control group of patients. The reduction of state anxiety with music could be due to either a distraction from the potentially uncomfortable procedure to the more pleasant sensation of the music itself $(31,32)$ or through actions mediated via decreased activity of the sympathetic nervous system and/or release of endorphins (33, 34).

The addition of music to the performance of a pleural procedure did not result in any added procedure related time. For any intervention this is an important finding. The relevance being that a simple intervention such as this, will only be accepted if it does not add to the workload of the proceduralist and assistant. For a change in practice to become widely accepted, it must be beneficial to patients but not at the expense of the healthcare staff caring for the patients. 
Limitations of our study warrant further comment. In our study the proceduralist could not be blinded to the intervention of music during the procedure. Our study design of using ear-bud headphones and laptop for streaming music made it impossible for the proceduralist to be blinded. However, we believe that we have minimised any potential bias by ensuring that the questionnaires were completed by patients when the proceduralist was not in the room. A possible concern regarding the provision of music during pleural procedures is the potential to impair communication between the medical team and the patient. We did not assess for this outcome, however anecdotally, clinicians performing the procedure did not report any impediments to communication in patients listening to music. Also, no complications were observed in any of the patients. It is nonetheless important to ensure that the sound level is such that the patient is able to hear the proceduralist or that an assistant is able to manipulate the headphones when required. Anxiety and pain was assessed prior to and at the conclusion of the pleural procedure. It was not possible to perform the STAI questionnaire during the procedure given the time required to complete the STAI and that this would distract from the intervention (i.e. music). It is therefore not possible to comment on the level of anxiety during the procedure itself. However, we believe that the post-procedure score is likely to be an accurate surrogate. Previous studies that evaluated music to reduce procedure related anxiety have evaluated the option of either patient choice of music or investigator choice of music (5-10, 14-16). Interestingly not all studies report that music reduces procedure related anxiety among patients. A possible explanation probably relates to patient preference, i.e. personal preference about music provides not only relaxation but also a sense of situational empowerment. In our study patients randomised to the music intervention were able to choose their music genre. However this may not be possible in other situations where internet connectivity is suboptimal and hence may reduce the widespread applicability of our study results. While 
the results of our study are interesting, they must be interpreted with caution until they are replicated and validated in a larger multi-centre study. Future research projects may also consider evaluating the impact of listening to music during pleural procedures on complication rates, impact on the workflow of physicians and nurses and an accurate costbenefit analysis of music as a possible non-pharmacological anxiolytic.

\section{Conclusion}

The success of a pleural procedure is reliant on pre-procedure planning, an adequately informed patient and operator experience. We demonstrate in this study that the addition of music is an effective adjunct to reduce patient anxiety, an often over-looked complication of invasive procedures. Recent technological advances have made vast catalogues of music easily and widely accessible further reducing the impediments for the provision of this non-pharmacological (possible) anxiolytic to all patients undergoing pleural procedures. 


\section{References}

1. Corcoran JP, Psallidas I, Wrightson JM, Hallifax RJ, Rahman NM. Pleural procedural complications: prevention and management. Journal of Thoracic Disease. 2015;7(6):1058-67.

2. Luketich J, Kiss M, Hershey J, Urso G, Wilson J, Bookbinder M, et al. Chest tube insertion: a prospective evaluation of pain management. The Clinical Journal of Pain. 1998;14(2):152-4.

3. Simons RJ, Baily RG, Zelis R, Zwillich CW. The Physiologic and Psychological Effects of the Bedside Presentation. N Engl J Med. 1989;321(18):1273-5.

4. Johnson JE, Morrissey JF, Leventhal H. Psychological preparation for an endoscopic examination. Gastrointest Endosc. 1973;19(180-181).

5. Triller N, Damjan E, Duh S, Marija Petrinec P, Kosnik M. Music during Bronchoscopic Examination: the Physiological Effects. Respiration. 2006;73(1):95-9. 6. Dubois JM, Bartter T, Pratter MR. Music improves patient comfort level during outpatient bronchoscopy. Chest. 1995;108(1):129-30.

7. Kotwal MR, Rinchhen CZ, Ringe VV. Stress Reduction Through Listening to Indian Classical Music During Gastroscopy. Diagnostic and Therapeutic Endoscopy. 1998;4(4):191-7.

8. Colt HG, Powers A, Shanks TG. EFfect of music on state anxiety scores in patients undergoing fiberoptic bronchoscopy. Chest. 1999;116(3):819-24.

9. Lee DWH, Chan K-W, Poon C-M, Ko C-W, Chan K-H, Sin K-S, et al. Relaxation music decreases the dose of patient-controlled sedation during colonoscopy: A prospective randomized controlled trial. Gastrointest Endosc. 2002;55(1):33-6.

10. Smolen D, Topp R, Singer L. The effect of self-selected music during colonoscopy on anxiety, heart rate, and blood pressure. Appl Nurs Res. 2002;15(3):126-36.

11. Ovayolu N, Ucan O, Pehlivan S, Pehlivan Y, Buyukhatipoglu H, Cemil Savas M, et al. Listening to Turkish classical music decreases patients’ anxiety, pain, dissatisfaction and the dose of sedative and analgesic drugs during colonoscopy: A prospective randomized controlled trial. World J Gastroentero. 2006;12(46):7532-6.

12. Vanderboom T. Does Music Reduce Anxiety During Invasive Procedures With Procedural Sedation? An Integrative Research Review. Journal of Radiology Nursing. 2007;26(1):15-22. 
13. Costa A, Montalbano LM, Orlando A, Ingoglia C, Linea C, Giunta M, et al. Music for colonoscopy: A single-blind randomized controlled trial. Digestive and Liver Disease. 2010;42(12):871-6.

14. Danhauer SC, Vishnevsky T, Campbell CR, McCoy TP, Tooze JA, Kanipe KN, et al. Music for patients with hematological malignancies undergoing bone marrow biopsy: a randomized controlled study of anxiety, perceived pain, and patient satisfaction. Journal of the Society for Integrative Oncology. 2010;8(4):140-7.

15. Koelsch S, Fuermetz J, Sack U, Bauer K, Hohenadel M, Wiegel M, et al. Effects of Music Listening on Cortisol Levels and Propofol Consumption during Spinal Anesthesia. Frontiers in Psychology. 2011;2:58.

16. Yeo JK, Cho DY, Oh MM, Park SS, Park MG. Listening to Music During Cystoscopy Decreases Anxiety, Pain, and Dissatisfaction in Patients: A Pilot Randomized Controlled Trial. J Endourol. 2013;27(4):459-62.

17. Chang YH, Oh TH, Lee JW, Park SC, Seo IY, Jeong HJ, et al. Listening to Music during Transrectal Ultrasound-Guided Prostate Biopsy Decreases Anxiety, Pain and Dissatisfaction in Patients: A Pilot Randomized Controlled Trial. Urol Int. 2015;94(3):33741.

18. Bell GD. Premedication, preparation, and surveillance. Endoscopy. 2002;34(1):212.

19. Andrada JM-C, Vidal AA, Aguilar-Tablada TC, Reina IG, Silva L, Guinaldo AR, et al. Anxiety during the performance of colonoscopies: modification using music therapy. Eur J Gastroenterol Hepatol. 2004;16(12):1381-6.

20. Wang MC, Zhang LY, Zhang YL, Zhang YW, Xu XD, Zhang YC. Effect of Music in Endoscopy Procedures: Systematic Review and Meta-Analysis of Randomized Controlled Trials. Pain Medicine. 2014;15(10):1786-94.

21. Speilberger C. Manual for the state-trait anxiety inventory (form Y). Palo Alto, CA: Consulting Psychologists Press; 1987.

22. Scott A. Managing anxiety in ICU patients: the role of pre-operative information provision. Nurs Crit Care. 2004;9(2):72-9.

23. Daub D, Kirschner-Hermanns R. Reduction of preoperative anxiety: music as an alternative to pharmacotherapy. Anaesthesist 1988;37:594-7. 
24. Agarwal A, Ranjan R, Dhiraaj S, Lakra A, Kumar M, Singh U. Acupressure for prevention of pre-operative anxiety: a prospective, randomised, placebo controlled study. Anaesthesia. 2005;60(10):978-81.

25. Wright KD, Stewart SH, Finley GA, Buffett-Jerrott SE. Prevention and Intervention Strategies to Alleviate Preoperative Anxiety in Children. Behav Modif. 2007;31(1):52-79.

26. Dileo C. Effects of music and music therapy on medical patients: a meta-analysis of the research and implications for the future. J Soc Integr Oncol. 2006;4(2):67-70.

27. Bradt J, Dileo C. Music for stress and anxiety reduction in coronary heart disease patients. Cochrane Database of Systematic Reviews. 2009(2).

28. Bradt J, Dileo C, Grocke D. Music interventions for mechanically ventilated patients. Cochrane Database of Systematic Reviews. 2010(12).

29. Bradt J, Dileo C, Grocke D, Magill L. Music interventions for improving psychological and physical outcomes in cancer patients. Cochrane Database of Systematic Reviews. 2011(8).

30. Bradt J, Dileo C, Shim M. Music interventions for preoperative anxiety. Cochrane Database of Systematic Reviews. 2013(6).

31. Mark M. Patient anxiety and modern elective surgery: a literature review. J Clin Nurs. 2003;12(6):806-15.

32. Nilsson U. The Anxiety- and Pain-Reducing Effects of Music Interventions: A Systematic Review. AORN J. 2008;87(4):780-807.

33. Arslan S, Özer N, Özyurt F. Effect of music on preoperative anxiety in men undergoing urogenital surgery. Aust J Adv Nurs. 2008;26(2):46-54.

34. Lee O, Chung Y, Chan M, Chan W-K. Music and its effect on the physiological responses and anxiety levels of patients receiving mechanical ventilation: a pilot study. $\mathrm{J}$ Clin Nurs. 2005;14(5):609-20. 


\section{Tables}

Table 1: Participant Characteristics

\begin{tabular}{|c|c|c|c|}
\hline & $\begin{array}{l}\text { Music Group } \\
(\mathrm{N}=30)\end{array}$ & $\begin{array}{l}\text { Control group } \\
(\mathrm{N}=30)\end{array}$ & p-value \\
\hline Age, mean \pm SD (years) & $65 \pm 15$ & $68 \pm 13$ & 0.234 \\
\hline Female sex, $\mathrm{n}(\%)$ & $16(53)$ & $14(45)$ & 0.797 \\
\hline Site of pleural effusion, $\mathrm{n}(\%)$ & & & 1.00 \\
\hline Right & $19(63)$ & $19(63)$ & \\
\hline Left & $11(37)$ & $11(37)$ & \\
\hline Proceduralist, n(\%) & & & 0.635 \\
\hline Junior House Officer (PGY2-4)** & $8(27)$ & $5(17)$ & \\
\hline Advanced trainee (PGY4+) & $18(60)$ & $20(67)$ & \\
\hline $\begin{array}{l}\text { Senior Medical Officer (Respiratory } \\
\text { Medicine Consultant) }\end{array}$ & $4(13)$ & $5(17)$ & \\
\hline $\begin{array}{l}\text { Undergone Pleural Procedures } \\
\text { Previously (n\%) }\end{array}$ & $7(23)$ & $15(50)$ & 0.060 \\
\hline \multicolumn{4}{|l|}{ Type of Procedure Performed } \\
\hline Pleural aspiration & $5(17)$ & $8(27)$ & 0.499 \\
\hline Intercostal Catheter & $24(80)$ & $20(67)$ & \\
\hline Indwelling Pleural Catheter & $1(3)$ & $2(7)$ & \\
\hline Aetiology of Pleural Effusion & & & 0.480 \\
\hline Malignancy & $20(67)$ & $19(63)$ & \\
\hline Parapneumonic effusion & $7(23)$ & $8(27)$ & \\
\hline Pneumothorax & $3(10)$ & 0 & \\
\hline Cardiac failure & 0 & $2(7)$ & \\
\hline Benign asbestos pleural effusion & 0 & $1(3)$ & \\
\hline \multicolumn{4}{|l|}{ Pleural Procedure Complications } \\
\hline Vasovagal syncope & 0 & 0 & \\
\hline Iatrogenic haemothorax & 0 & 0 & \\
\hline
\end{tabular}




\begin{tabular}{|l|l|l|l|}
\hline Iatrogenic pneumothorax & 0 & 0 & \\
\hline Pleural space infection & 0 & 0 & \\
\hline & & & \\
\hline
\end{tabular}

*SD: standard deviation; PGY: post-graduate year

**Procedures performed by House Officers (PGY2-4) were performed under the mandatory supervision of either an advanced trainee (PGY4+) or consultant in respiratory medicine. 
Table 2: Physiological and Subjective Measurements According to Intervention Status

\begin{tabular}{|c|c|c|c|}
\hline & $\begin{array}{l}\text { Music Group } \\
(\mathrm{N}=30)\end{array}$ & $\begin{array}{l}\text { Control group } \\
(\mathrm{N}=30)\end{array}$ & p-value \\
\hline \multicolumn{4}{|l|}{ Pre-procedure } \\
\hline Pulse Mean \pm SD (beats/min) & $95 \pm 15$ & $85 \pm 15$ & 0.010 \\
\hline SBP, Mean \pm SD (mmHg) & $130 \pm 16$ & $134 \pm 20$ & 0.500 \\
\hline DBP, Mean \pm SD (mmHg) & $78 \pm 9$ & $79 \pm 10$ & 0.917 \\
\hline State Anxiety, Mean \pm SD & $48 \pm 13$ & $42 \pm 10$ & 0.075 \\
\hline Trait Anxiety, Mean \pm SD & $36 \pm 11$ & $36 \pm 9$ & 0.871 \\
\hline $\begin{array}{l}\text { Duration of procedure, Mean } \pm \text { SD } \\
(\min )\end{array}$ & $58 \pm 27$ & $56 \pm 30$ & 0.675 \\
\hline \multicolumn{4}{|l|}{ Patient Satisfaction, median (IQR) } \\
\hline Mean pain score (VAS) & $3.2 \pm 2.7$ & $2.5 \pm 2.9$ & 0.800 \\
\hline $\begin{array}{l}\text { Willingness to undergo procedure } \\
\text { (VAS) }\end{array}$ & $9.4 \pm 1.3$ & $9.3 \pm 1.2$ & 0.268 \\
\hline Satisfaction (VAS) & $9.5 \pm 1.3$ & $8.4 \pm 1.2$ & 0.198 \\
\hline \multicolumn{4}{|l|}{ Post-procedure } \\
\hline Pulse Mean \pm SD (beats/min) & $89 \pm 19$ & $86 \pm 16$ & 0.520 \\
\hline $\begin{array}{l}\text { Systolic pressure, Mean } \pm \text { SD } \\
(\mathrm{mmHg})\end{array}$ & $121 \pm 13$ & $133 \pm 21$ & 0.020 \\
\hline $\begin{array}{l}\text { Diastolic pressure, Mean } \pm \text { SD } \\
(\mathrm{mmHg})\end{array}$ & $72 \pm 8$ & $77 \pm 9$ & 0.097 \\
\hline State Anxiety, Mean \pm SD & $34 \pm 11$ & $40 \pm 11$ & 0.040 \\
\hline Trait Anxiety, Mean \pm SD & $34 \pm 10$ & $35 \pm 10$ & 0.912 \\
\hline $\begin{array}{l}\text { Change in Pulse from baseline, } \\
\text { Mean } \pm \text { SD }\end{array}$ & $-6.9 \pm 10$ & $1.37 \pm 6.1$ & $<0.001$ \\
\hline $\begin{array}{l}\text { Change in SBP from baseline, } \\
\text { Mean } \pm \text { SD }\end{array}$ & $-8.6 \pm 11$ & $-1.13 \pm 18$ & 0.111 \\
\hline
\end{tabular}




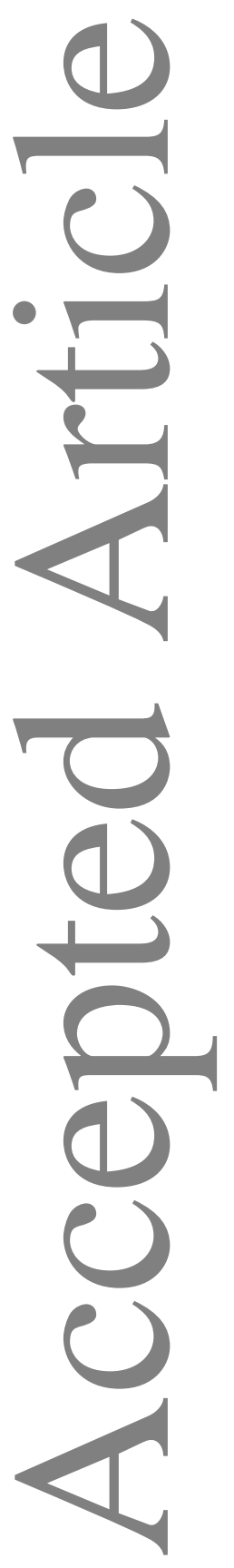

\begin{tabular}{|c|l|l|l|}
\hline $\begin{array}{c}\text { Change in DBP from baseline, } \\
\text { Mean } \pm \text { SD }\end{array}$ & $6.2 \pm 8.5$ & $2.5 \pm 11$ & 0.211 \\
\hline $\begin{array}{c}\text { Change in State Anxiety baseline, } \\
\text { Mean } \pm \text { SD }\end{array}$ & $-14 \pm 11$ & $-1.6 \pm 4.7$ & $<\mathbf{0 . 0 0 1}$ \\
\hline $\begin{array}{l}\text { Change in Trait Anxiety from } \\
\text { baseline, Mean } \pm \text { SD }\end{array}$ & $-1.9 \pm 3.3$ & $-1.1 \pm 2.9$ & 0.431 \\
\hline
\end{tabular}

*SD: standard deviation; SBP: Systolic Blood Pressure; DBP: Diastolic Blood Pressure 


\section{Figure Legends}

Figure 1: Participant flow through the study and allocation of interventions.

Figure 2: State Anxiety Scores in the Music (A) Group and Control Group (B). Each patients score is plotted pre- and post-pleural procedure.

Figure 3: Physiological parameters and effect of Music. Individual patient values are compared pre and post procedure in the Music (A, C and E) and the Control (B, D and F) group.

Supplementary Figure: Trait Anxiety Scores Pre and Post Pleural Procedure in the Music (A) Group and Control Group (B). 


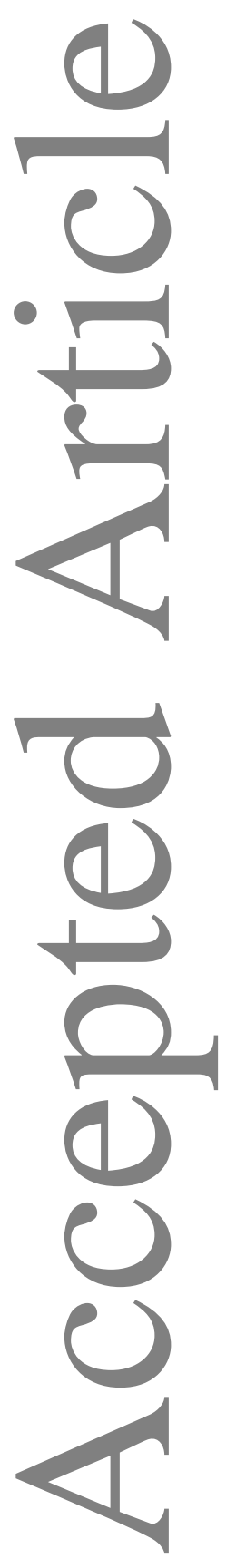

\section{Figure 1}




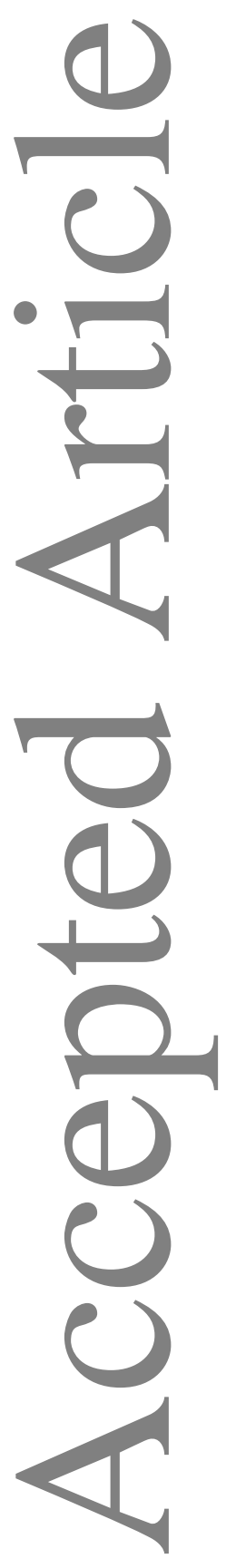

\section{Figure 2}

This article is protected by copyright. All rights reserved. 


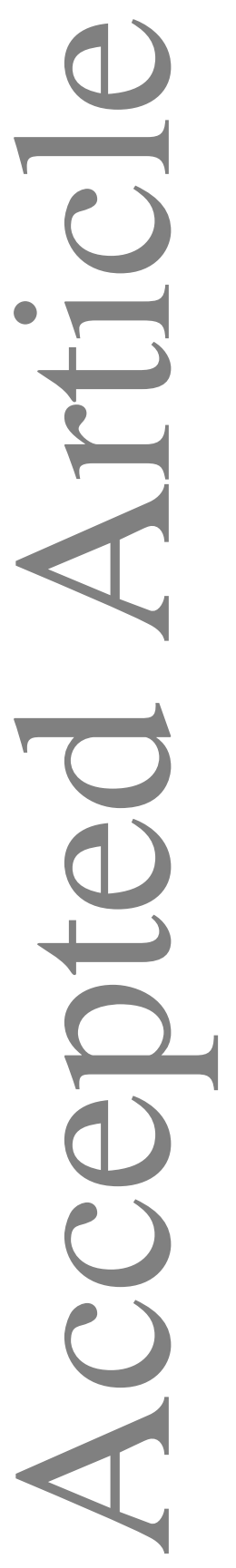

\section{Figure 3}


